\title{
A COMPARATIVE STUDY OF UTILIZING MOBILE-GIS TECHNOLOGY TO COLLECT ONLINE CRIME
}

\author{
H. Fadaei ${ }^{1, *}$, M. Bayazidi ${ }^{2}$ \\ ${ }^{1}$ Faculty Member of Amin University of Police, Iran - fadaei@me.com \\ ${ }^{2}$ Master of Science in Geosciences and Geosciences, Iran - m.bayzidy@gmail.com
}

KEY WORDS: Mobile-GIS, RTK, Global Positioning System, GIS, Crime Reporting

\begin{abstract}
:
Mobile-Geographic Information System (GIS) is one of the dimensions of these enhancements, which, due to its flexibility, its simplicity with traditional GIS systems, the need for less expertise and low cost, has brought this technology into a variety of areas. Mobile technologies using mobile devices is proving to be a more effective implementation for crime detection and monitoring. Mobile-GIS are operating within a wider range of GIS technologies, wireless technologies, and global positioning technology. The ability to use this system to report crime and control crime in cities has led different countries to use this system for easier and less costly reporting of citizens, and many developed countries use Mobile-GIS technology to do this. And they use this technology depending on their needs. In this research, Mobile-GIS applications in the five developed countries of the world are being studied and their disadvantages and advantages are discussed, and finally, regarding to society safety the possibilities and necessity of police department to develop such programs are discussed. In this study, we are proposing a crime reporting and management model using GIS technologies and review the all possibility and limitation to implementation are confronted in order to mitigate the challenges are faced by most developing countries in reducing the crime rates. A conceptual plan for constructing such a program in the police department has been proposed, which is suggested by using systems like Real-time kinematic (RTK) to improve the user's location to increase accuracy.
\end{abstract}

\section{INTRODUCTION}

The fight against crime is the biggest challenge for many countries. Every family and occupation is directly or indirectly affected by theft, vandalism (destruction of general emulsion without any reason), street violence and etc. Recent research shows the importance of using mobile devices as an efficient way to detect and report offenses. According to the World Bank, 51 percent of the world's population has access to the Internet in 2016, and 64 percent of the world's population has access to smartphones (World Bank, 2016). The statistic shows the number of Internet users in selected Middle Eastern countries as of June 2017. As of that month, Iran had 56.7 million internet users (Fig. 1).

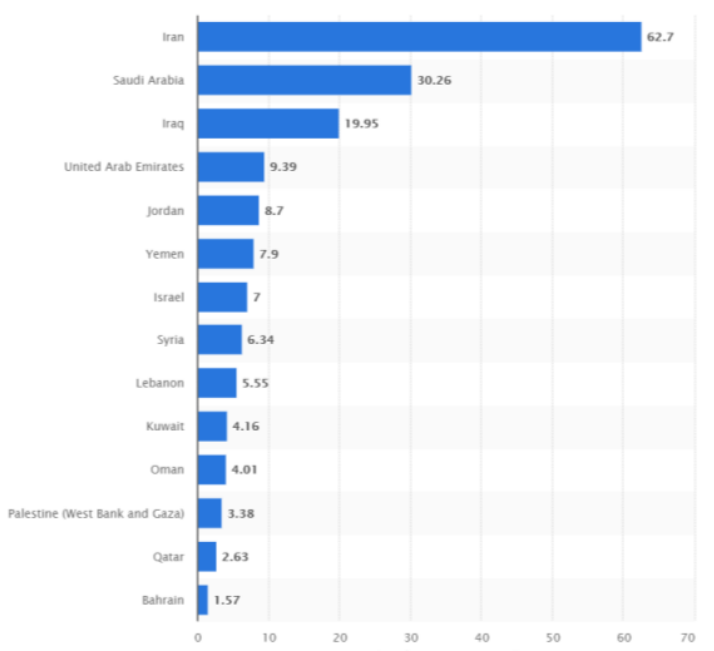

Figure 1: Number of internet users in the Middle East as of June 2017, by country (in millions) (Source:

https://www.statista.com/statistics/603061/number-of-internet-users-inmiddle-east-countries/)

The number of worldwide internet users, sorted by region. As of January 2019, East Asia accounted for 1 billion internet users, followed by Southern Asia with 803 million internet users (Fig. 2).

\footnotetext{
${ }^{*}$ Corresponding author
} 


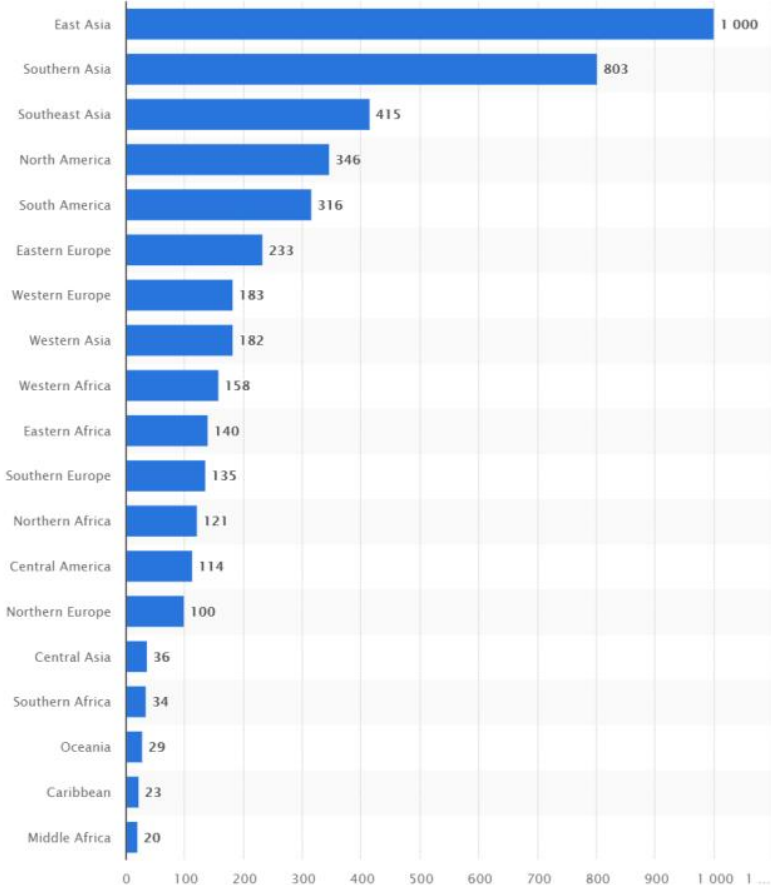

Figure 2: Number of worldwide internet users as of January 2019, by region (in millions) (Source:

https://www.statista.com/statistics/249562/number-of-worldwideinternet-users-by-region/)

Half the world's population has a mobile phone or tablet, and they can access to internet and can receive accurate geographic location using the Global Positioning System (GPS) system. Today, mobile phones do not just lead to making voice calls and sending short messages to other people. Today, many people in the community, especially young people, have come up with digital carriers with other people through mobile phones (Pew Research Center, 2015). Even today, many elderly people use these phones (Smith, 2014). Smartphones can store data such as physical movements and physical activity (through GPS data), sound, photos, and many physical parameters. Also, smartphones can access many of the parameters of body physiology by touching us on the phone (for example, placing the camera in front of us, moving your fingers to the phone's screen, blowing the air into the microphone when talking to the phone, etc. (Kumar et al.2013).

Important features of mobile phones, such as the growing use of mobile phones and their high technology, have greatly increased. Today, in many countries of the world, citizens are regarded as a very sensitive and important sensor for the collection of vital and accurate information (Kizza, 2019). However, in some cases, information is needed to collect, and the person needs to be sure of the accuracy of this information. Geographic Information System has entered a new stage in its evolutionary process, and growing the information technology, as well as need of the human community for advanced devices and advancements in hardware and software (Ramaprasad and Narayanan, 2019). One of the major advances in geographic information systems has been the development of mobile geospatial information systems in recent years, the geographic information systems have entered to the public domain, and its functions have increasingly entered into various areas of research, military and law enforcement, planning, management and so on (Yasobant, Vora, and Upadhyay, 2019). The use of Mobile-GIS is not unique to oil and gas companies and is used in many everyday life areas (Norton, 2018). Volunteer geographic information is an ever-growing scientific field for collecting spatial information through citizens. This term was first introduced by the researcher Michael Goodchild, who worked on user-centric content on the Web (Goodchild, 2007). The general idea of using citizens was to collect geographic information via local network to create, share and analyse geographic information by several computer devices (Papapesios, Ellul, Shakir and Hart, 2019). Famous examples that use the idea of volunteer geospatial information to collect spatial information can be found on websites like Wikimapia (web mapping), OpenStreetMap (OSM) Google Map. (Ballatore and Arsanjani, 2018). The popularity of mobile phones has led to the use of this tool in police intelligence to track down criminals as well as the specific criminals' pattern of movement are defined as a low-cost have been proposed (Albanna and Heeks, 2019). Discussing a system of mobile-GIS data to detect criminal activities and tracking criminals through their mobile phone can be interesting for police (Ajayakumar, Curtis, Smith and Curtis, 2019). for example in this system, police can send a short message to the person are looking for, which the offender or target person cannot aware of; then the return answer from the target phone can shows the exact location of the person in the network. This paper will discuss the technological aspects of the mobile GIS and will show some specific applications in other countries. Moreover, other related topics will be treated: how to make the mobile GIS context aware, how to integrate it with user positioning and object of interest location, how to face some problems (slow loading of images, connection costs and accuracy position) how to use it within a local wireless network, how to redefine maps and contexts by GML (Geographic Markup Language) (Jiang, and Yao, 2007). Also, other purpose of this study is to explore the various mobile crime data collection programs that have been used by GIS mobile technology and review the all possibility and limitation to implementation are confronted in order to mitigate the challenges are faced in reducing the crime rates. The ultimate goal of this study is to reduce the crime reporting by citizens.

\section{BACKGROUND RESEARCH}

Over the past few years, smartphones have been a growing interest in using the web and to collect and display information like geographically volunteered information. Websites such as Wikimapia, OpenStreetMap and Google Earth allow users to share their geospatial information, such as land use, transit paths, scenic sites, or historical sites, with the creation of a virtual environment (Ferguson, 2017). Mwiya et al. (2015), in an article entitled " Public Crime Reporting and Monitoring System Model Using GSM and GIS Technologies: A Case of Zambia Police Service", first reviewed the common reporting methods. The crime rate in Zambia and their research results show that $68 \%$ of the population report to police stations for reporting crimes, $30 \%$ report mobile crimes, and less than $1 \%$ of people report reporting services (Fig. 3). Horita et.al, (2015) in a study entitled "Decision Support System for Developing Volunteer Geographical Information on Flood Management in Brazil by Integrating This Information with Wireless Sensor Data" is a spatial decision support system designed to combine the sensor network with Wi-Fi and voluntary geospatial information support emergency decision-making. The observed results in a real scenario have shown that the use of volunteering geospatial data in combination with the Wi-Fi sensor network can be useful in managing flood risks. This WSN integration, VGI, can help decisions of critical decisionmaking organizations, since volunteering geography can be used to cover areas where the network is poorly-tuned or 
congested in a low-density environment. Schnabel and Cervone, (2013) in a study entitled "Improving the Estimation of the Progression of Water Currents by Combining Voluntary Geographical Measurement" by integrating voluntary geospatial data, land survey and digital land-based models created a new method for zoning natural hazards. It also showed that the use of a small amount of volunteering data, when combined with land survey data and digital model, could change the natural hazards zoning map. Also, volunteers' spatial distribution can make extensive detection of damaged environments.

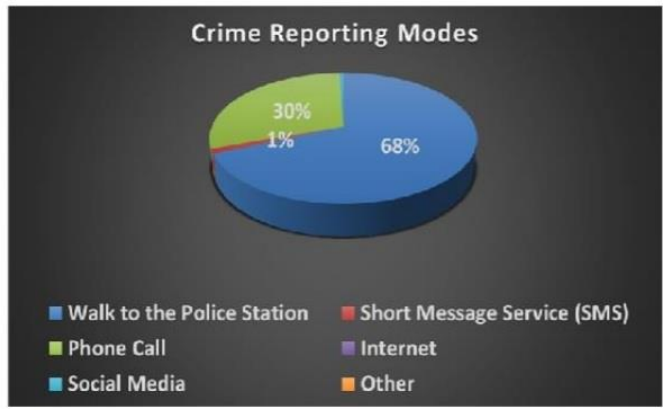

Figure 3: crime reporting modes by citizen (MWiya, et.al. 2015)

\section{METHODOLOGY}

Regarding the research topic, which is a comparative study, this study is a comparative study. In a comparative study, one or more features are studied among different methods. The statistical population in this study includes all the countries in the world, selected from the 10 most developed countries in the world that have been active in the field of using mobile-GIS to collect crime information and active mobile apps with good results. All documents in the field of research on the use of mobile-GIS to collect crime data globally found in the form of an article or dissertation on the internet or published as web pages have been investigated.

Generally, all crime reporting systems globally use the client/server method. The user's side includes a mobile app developed for android and iOS devices. In this way, the user (client) is the most important part of the program and all efforts should be directed towards attracting more users for reporting so that information (crime reporting) from both the dispersion and the numbers of geography location should be increased, and then the level of confidence increases to the system. The relationship between the database and the program should be programmed professionally to prevent the server from penetrating and has no bugs or errors. The programming languages used to design the server, which is the same as the language of communication between the other server components and the mobile-GIS application with the database; including the addition of data to the database, query, etc., are performed (Yang, et.al, 2019). Currently, the number of police departments using new technologies to create crime maps is very limited throughout the country, and the crime report is carried out in the traditional way, which is the same as referring to police departments, which slow down the process of pursuing crime. Creating an online system for reporting crime speeding offense report is very sensible.

\subsection{Mobile application diagram}

In general, in the first step: (1) the user first sends crime reporting using a mobile application designed with high accurate geographic coordinates to the police stations. (2) The nearest police station will be sending a police officer to the exact location of the crime for tracking operation. (3) Police officer sends the more details of crime to police Center and local police station for more action if need it. (4) Finally policemen performance feedback about the crime to the police station and police headquarter will be sent by the user (Fig 4). In more details of mobile-GIS application by citizens could be found in bellow diagram (Fig 5). Also, we studied the mobileGIS systems in the world that have been collecting crime reports from people.

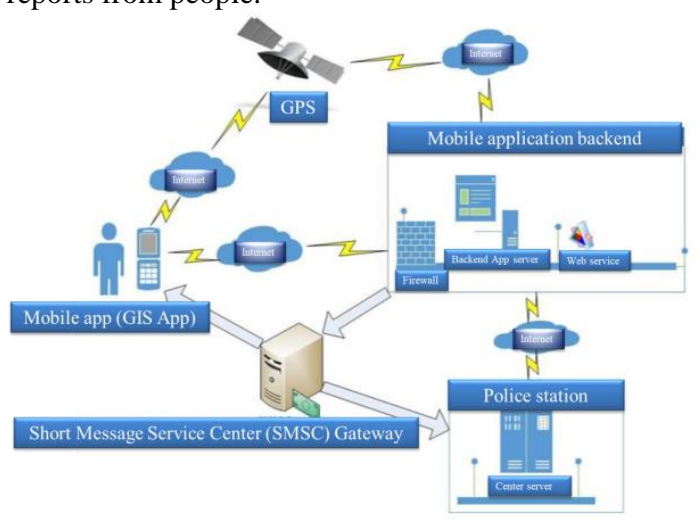

Figure 4: The general method of crime data collection by mobile-GIS
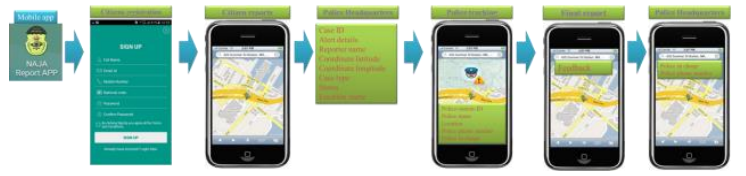

Figure 5: The detail of utilize Mobile-GIS app

The program systems of Mobile-GIS in the 6 country have been reviewed. Finally, recommended the suggestions to launch the Mobile-GIS system for collecting crime data in the Police department.

\subsection{Vic Mobile App}

The Victoria Police Mobile App (British Columbia, Canada) has been developed by the Victoria Police Department and is now downloadable and installed at the Google store and has downloaded and installed nearly 100,000 people. If your child is lost, this program will help you inform the police. You can use the program if you want to report the theft that the perpetrator is unknown and if you want to always see Victorian police news online and you know the news from this department. Use this app (Fig. 6).

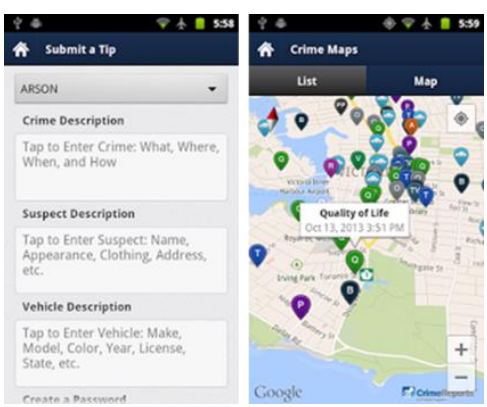

Figure 6: the Mobile-Vic App 


\subsection{Tip Submit App}

In the state of New Orleans, the United States has developed an online crime program that is currently operating under the Android operating system and allows users to send online crime information. The program enables online police officers to discuss problems with people without a physical presence at the police stations. The system also allows users to report online crime by using a mobile phone, and users can report their pictures, videos and messages to police stations along with a precise geographical location. The system's excellent features include awarding cash prizes to individuals who give police precinct details of the location of criminals, drug traffickers, drug stores, etc. Prizes for such reports range from $\$ 1,000$ to $\$$ 2,000 , which are concealed by hiding the person's reporting information (Fig. 7).

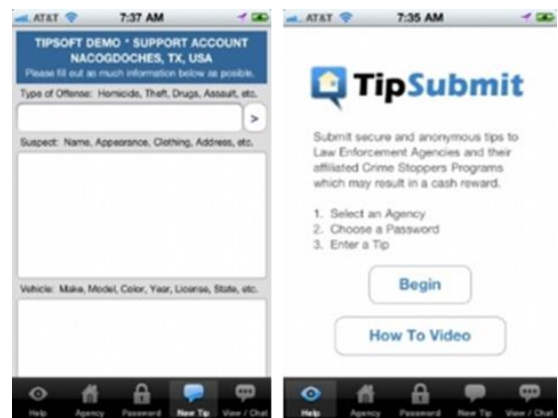

Figure 7: Tip Submit App

\subsection{Crime Mapper App}

The Crime Mapper app allows its users in the United Kingdom to view crime reports based on public data in the country. The reports presented in this program are based on data from 43 counties in the UK, the UK transportation system and Northern Ireland and the Justice Department. Users can see all registered crime information in the application by a click on registered events. It also shows parts of the cities that have the highest incidence of reported crime and are at high risk areas. You can also print maps, search the crime type in the area, review the latest reported crime, and determine the distance between your place of residence and the high-risk areas (Fig. 8).

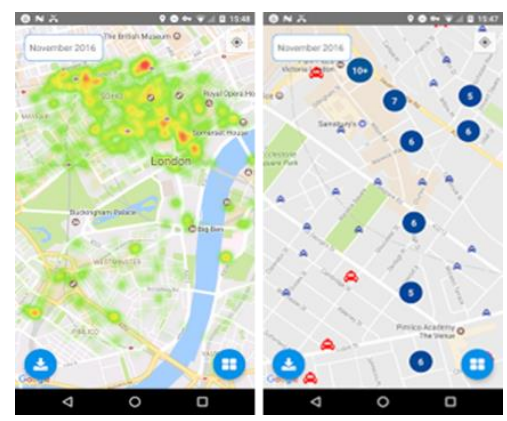

Figure 8: Crime mapper

\subsection{Crime Reporters App}

The Crime Reporters app is Android-based and iOS-based apps that use North American cities to report crimes and sexual assaults. It also launches a window to a largest sex offender's website in the world and allows access to all information about it to its users. It also allows you to contact more than 1100 legal companies to get free and online advice on crimes and, in particular, sexual offenses, and use it in all 50 North American countries. The program has been installed and used more than 500,000 times (Fig. 9).

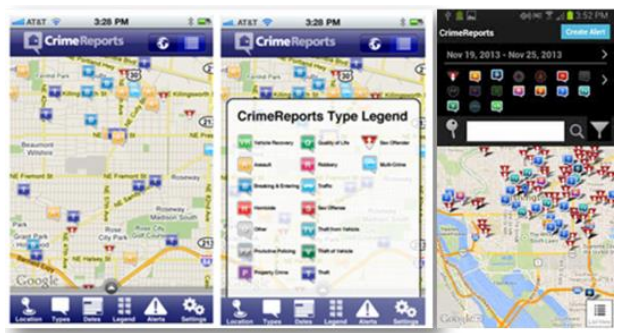

Figure 9: Crime reporters

\subsection{Hotline JAIS App}

The JAIS hotline program is used to report easy and easy crime in Malaysia's Selengur province. The program has been developed for more people in the area from Malaysia to police stations. This app is currently running under the Android operating system. This program requires a set of predefined information such as name, address, telephone number, etc., which the user must first $\log$ in to in order to be able to report crime. In this program, any report should be accompanied by credible evidence and evidence to be considered. It can also answer questions from users on how to report crimes, legitimacy of these reports, and legitimacy for Islam, and so on (Fig. 10).
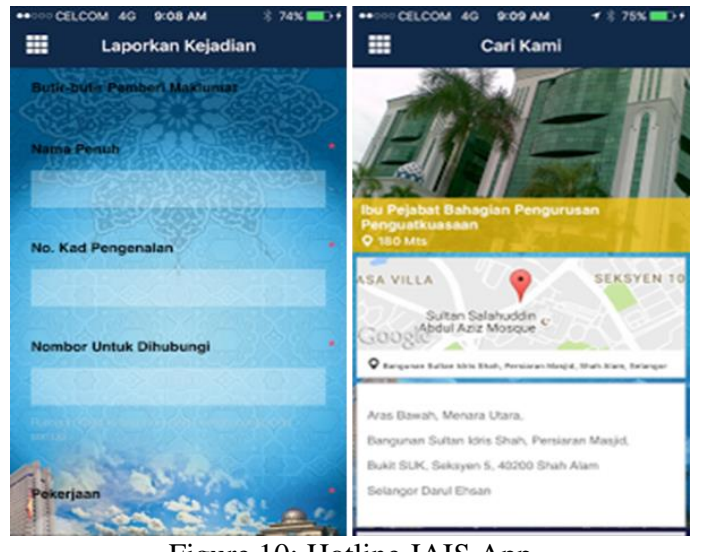

Figure 10: Hotline JAIS App

\subsection{Citizen COP App}

The Citizen COP is a mobile application running on Android and iOS mobile devices to protect citizens and prevent crime in a free environment that encourages volunteers to report crime at the level of Indian cities. This app works perfectly for most cities in India and is limited to the rest of the world (Fig. 11). 


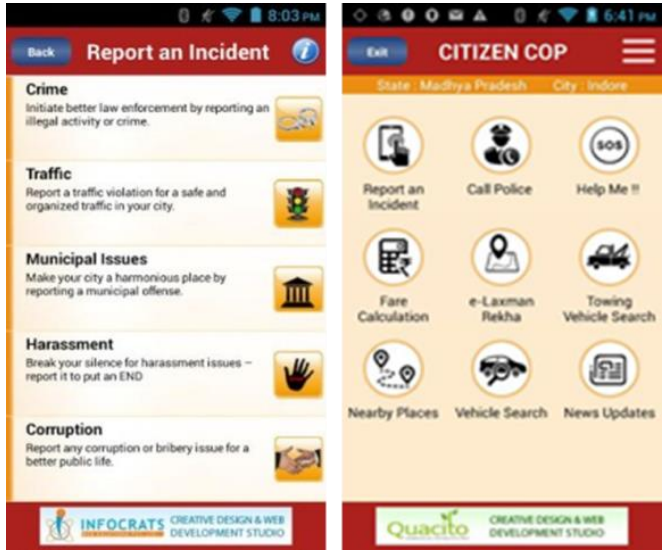

Figure 11: Citizen COP App

\section{RESULTS}

\subsection{Advantage of these mobile application}

1. Showing offenses in the form of a map has many advantages, including clarifying the level of crime, timely information to the public, etc.

2. This system allows for two-way communication between the police and the ordinary people, which is very suitable for improving the relations between the police and the people.

3. Ask for emergency help.

4. Request help from friends by choosing an option to help you in critical situations.

5. Find the route and phone number of the nearest police station.

6. The user can search for their abducted or stolen items by registered police with the police on the basis of license plate, serial number etc. (Table. 1).

\subsection{Disadvantage of these mobile application}

1. Displaying crime-related information as a map can create fears among people and create fear among residents of some areas among people. While many people in these areas do not sabotage people, they are among the good and legal citizens.

2. In this system, any user can easily download and install the program to access the system and access information such as photo and video, and only the user's email information are used to report the crime. The system should have an initial registration and information such as name and mobile number is received from the user to contact him in case of a problem with the information contained in the contact and resolve the errors. 3. Access restrictions for users

4. Showing high-risk areas for residents of those areas of fear and fear (Table. 1).

Table 1: properties of all APP in crime data collecting

\begin{tabular}{|c|c|c|c|c|c|c|c|c|c|}
\hline Applicable & 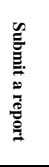 & 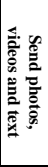 & 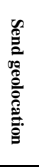 & 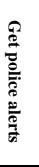 & 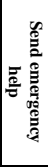 & 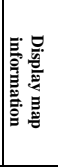 & 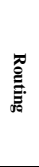 & 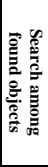 & 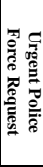 \\
\hline Vic Mobile & $\checkmark$ & $\checkmark$ & $\checkmark$ & $\checkmark$ & $x$ & $\checkmark$ & $x$ & $\checkmark$ & $x$ \\
\hline Tip Submit & $\checkmark$ & $\checkmark$ & $\checkmark$ & $\checkmark$ & $x$ & $\checkmark$ & $x$ & $\checkmark$ & $x$ \\
\hline Crime Mapper & $\checkmark$ & $\checkmark$ & $\checkmark$ & $\checkmark$ & $x$ & $\checkmark$ & $\checkmark$ & $\checkmark$ & $x$ \\
\hline Crime Reporters & $\checkmark$ & $\sqrt{ }$ & $\sqrt{ }$ & $\sqrt{ }$ & $x$ & $\checkmark$ & $\bar{x}$ & $x$ & $\bar{x}$ \\
\hline Hotline JAIS & $\checkmark$ & $\checkmark$ & $\checkmark$ & $\checkmark$ & $x$ & $\checkmark$ & $x$ & $\checkmark$ & $x$ \\
\hline Citizen COP & $\checkmark$ & $\checkmark$ & $\checkmark$ & $\checkmark$ & $x$ & $\checkmark$ & $x$ & $\checkmark$ & $x$ \\
\hline
\end{tabular}

\subsection{Overall result}

The overall results of this research can be divided into the following categories:

1. Overall outcomes: The overall results of the world-wide system reviews of using mobile phones in the crime report show a high potential, and most advanced countries in the world use this potential as their best.

2. Partial results: The partial results of these applications were used to design such a system in Iran.

\section{DISSCUTION}

According to the previous section, many developed countries in the world contributed people as volunteers in geography terms especially in GIS. Nowadays they established some mobile application by assistance of people as volunteers in society in the field of crim helps to reduce crime (Pitarch-Garrido, 2019). These programs allow people to quickly send reports of people without police presence and severely reduce the time of the crime.

This app has two prominent features:

1. Collection of crime information using people

2. Reduce the time of the crime report (via the Internet) by eliminating the physical presence of the person with the police departments.

3. Reduce the cost of police

It is also possible to create an application to control crime.

The application is mobile (Java, Android, iOS) that receive information from the user (reporting person) and logs in to the server for future processing.

After building the application, we need to have a server to store the information sent by the user and to process the data. The first step in storing the data is to have a geo-database. After saving spatial data in the geo-database, it is now time to process data and display information on online maps, processing and displaying information is usually done by the servers of the map. Geo-server is very suitable because it is open source and supports both free and many spatial processing.

According to the GPS satellite network, this allows mobile users to quickly access their geographical location. Positioning is also very easy and the user does not need to enter information such as street, alley, etc. With just one click, it can send the images and text of your report along with the exact location to the server. But here's a big problem, about the accuracy of the global positioning system for Iran, given the sanctions imposed by the United States. The average accuracy of GPS for Iran is between 30 and 50 meters, and it is not very useful for sensitive work such as reporting the exact location of the crime. The solution addressed to this problem is to use a local positioning system with precision centimeters. This position system is Realtime kinematic (RTK) positioning is a satellite navigation technique used to enhance the precision of position data derived from satellite-based positioning systems. The Information and Communication Technology Organization (ICT), as the trustee of the establishment of the necessary infrastructure for spatial information in the municipality of Tehran in 2010, has set up a network for determining the precise location and location of the city of Tehran. For the complete coverage of the city of Tehran, six main stations have been selected in the composition of this network. The possibility of transmitting information between base stations, these points should have good communication infrastructure. The same infrastructure has been used to link the main Real-time kinematic (RTK) positioning is a satellite navigation technique used to enhance the precision of position data derived from satellite-based positioning systems (Fig. 12). 


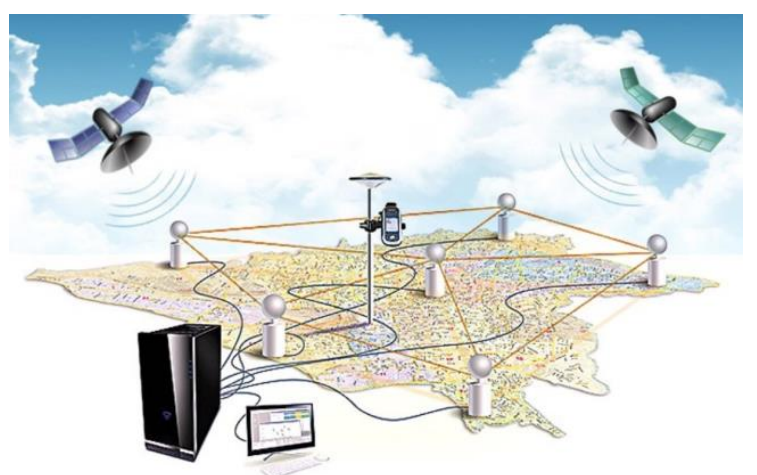

Figure 12: Instantaneous positioning system (Real-time kinematic (RTK) positioning system)

The benefits of network RTK include the following:

1. Full coverage of the area

2- Access to precision centimetres in the minimum possible time

3- Minimize the dependency of the accuracy of corrections to the receiver distance from the main station

4. Achieving uniformity of accuracy in points within the network

5. The need for lower main stations and therefore cost reduction

6. Reducing the number of short lines and improving the accuracy of the closure of mapping networks

7. The ability to easily remove irregular natural boundaries as a very precise control operation.

8. Fast, accurate and easy to use by surveyors

\subsection{Output}

The maps obtained from this method can be used to extract the following useful information:

1. The zoning map of crime in the city (map robbery, murder, stealing bags, etc.)

2. Zoning map the time of the crime, the more crimes occur at specific times

3. Optimal control of police patrols to achieve the best performance

\section{ACKNOWLEDGEMENTS}

The research was carried out with the support of the Amin Police University. I appreciate to Mrs. Paydar for her excellent editing.

\section{REFERENCES}

Ajayakumar, J., Curtis, A., Smith, S., \& Curtis, J. (2019). The Use of Geonarratives to Add Context to Fine Scale Geospatial Research. International journal of environmental research and public health, 16(3), $515 . \quad$ DOI: https://doi.org/10.3390/ijerph16030515

Albanna, B., \& Heeks, R. (2019). Positive deviance, big data, and development: A systematic literature review. The Electronic Journal of Information Systems in Developing Countries, 85(1), e12063. DOI: https://doi.org/10.1002/isd2.12063

Ballatore, A., \& Jokar Arsanjani, J. (2018). Placing Wikimapia: an exploratory analysis. International Journal of Geographical Information Science, 1-18. Retrieved from: https://github.com/andrea-ballatore/WikimapiaResearch
Ferguson, L. (2017). Mapping and Managing Natural and Cultural Assets. SHAPE Report. Deliverable. Retrevied form: http://shape.interregnpa.eu/subsites/SHAPE/WPt2_Capitalising _on_assets/DT2.1.1_Report_on_mapping_and_managing_asset s_and_assessing_climate_change_impacts.pdf.

Goodchild, M.f, (2008). Commentary: whither VGI? GeoJournal, 72, 239-244. DOI: https://doi.org/10.1007/s10708008-9190-4

Goodchild, M.F. (2007). Citizens as sensors: the world of volunteered geography. GeoJournal, 69, 211-221. DOI: https://doi.org/10.1007/s10708-007-9111-y

Govindaraj, S., Letier, P., Chintamani, K., Gancet, J., Jimenez, M. N., Esbrí, M. Á., ... \& Coelho, A. (2017). Command and Control Systems for Search and Rescue Robots. In Search and Rescue Robotics-From Theory to Practice. IntechOpen. Retrieved from: https://www.intechopen.com/download/pdf/56086

Horita, F. E., de Albuquerque, J. P., Degrossi, L. C., Mendiondo, E. M., \& Ueyama, J. (2015). Development of a spatial decision support system for flood risk management in Brazil that combines volunteered geographic information with wireless sensor networks. Computers \& Geosciences, 80, 84-94. DOI: https://doi.org/10.1016/j.cageo.2015.04.001

http://citizencop.org[accessed:06/03/2017

http://play.google.come/store/apps/crimereporters[accessed:05/ $03 / 2017$

http://play.google.come/store/apps/HotlineJAIS[accessed:05/03/ 2017

http://www.CrimeMapping.com/heelp[accessed:08/03/2017

http://www.crimemaps.org.uk[accessed:06/03/2017

Jiang, B., \& Yao, X. (2007). Location based services and GIS in perspective. In Location based services and telecartography(pp. 27-45). Springer, Berlin, Heidelberg. DOI: https://doi.org/10.1016/j.compenvurbsys.2006.02.003

Kizza, J. M. (2019). Evolving Realities: Ethical and Secure Computing in the New Technological Spaces. In Ethical and Secure Computing (pp. 209-228). Springer, Cham. DOI: https://doi.org/10.1007/978-3-030-03937-0_10

Kumar S, Nilsen W, Abernethy A, Atienza A, Patrick K, Pavel M, Riley WT, Shar A, Spring B, Spruijt--Metz D, Hedeker D, Honavar V, Kravitz RL, Lefebvre RC, Mohr DC, Murphy SA, Quinn C, Shusterman V, \& Swendeman D. Mobile Health Evidence Workshop - Exploring Innovative Methods to Evaluate the Efficacy and Safety of Mobile Health, American Journal of Preventive Medicine, 45(2):228--236, Oct 2013a.DOI: https://doi.org/10.1016/j.amepre.2013.03.017

Mwiya, M., Phiri, J., \& Lyoko, G. (2015). Public Crime Reporting and Monitoring System Model Using GSM and GIS Technologies: A Case of Zambia Police Service. International Journal of Computer Science and Mobile Computing, 4(11), 226. Retrieved from: https://pdfs.semanticscholar.org/7835/60a1fa21a61d8453eed06 528661a990d77dc.pdf. 
Norton, E. J. (2018). Investigating the Role of Geospatial Technologies as a Supplement to Environmental Education: Development of an Environmental Data Collection Application and Its Implementation in the Classroom. Retrieved from: https://trace.tennessee.edu/utk_gradthes/5108

Papapesios, N., Ellul, C., Shakir, A., \& Hart, G. (2019). Exploring the use of crowdsourced geographic information in defence: challenges and opportunities. Journal of Geographical Systems, 1-28.DOI: https://doi.org/10.1007/s10109-018-0282-5

Paul Heaton and Luis Garicano, "Do ComputersHelp Police fight crime?CentrePieceWinter2007/08", Availableat:http://cep.lse.ac.uk/pubs/download/cp247.pdf Pew Research Center. Mobile technology fact sheet. Available at: http://www.pewinternet.org/fact---sheets/Mobile--technology---fact---sheet/,2015

Pitarch-Garrido, M. D. (2019). The Role of Geographic Technologies in the Measure of Spatial Equity. Twenty-First Century Solutions for Old Geographical Issues. In Geospatial Challenges in the 21st Century (pp. 189-211). Springer, Cham. DOI: https://doi.org/10.1007/978-3-030-04750-4_10

Portio Research, "Smartphone Futures 2012-2016". Retrieved from: www.portioresearch.com/media/2548/SPF12-16 BROC.pdf

Ramaprasad, N. N., \& Narayanan, P. (2019). Volunteered Geographic Information System and Its Contribution in Service Sector Employment. In Geographic Information Systems. IntechOpen. DOI: https://doi.org/10.5772/intechopen.82004

Schnebele, E., \& Cervone, G. (2013). Improving remote sensing flood assessment using volunteered geographical data. Retrieved from: http://hdl.handle.net/1920/8824

Smith A. Older adults and technology use. Available at: http://www.pewinternet.org/2014/04/03/older--adults--and-technology-use, 2014.

Yang, C., Fu, P., Goodchild, M. F., \& Xu, C. (2019). Integrating GIScience Application Through Mashup. In CyberGIS for Geospatial Discovery and Innovation (pp. 87112). Springer, Dordrecht. DOI: https://doi.org/10.1007/97894-024-1531-5_6

Yasobant, S., Vora, K. S., \& Upadhyay, A. (2019). Geographic information system applications in public health: Advancing health research. In Healthcare Policy and Reform: Concepts, Methodologies, Tools, and Applications (pp. 538-561). IGI Global. DOI: https://doi.org/10.4018/978-1-5225-6915-2.ch026 